\title{
Community Service-Learning in Canada: One Size Does Not Fit All
}

\author{
Renate Kahlke and Alison Taylor
}

\begin{abstract}
Community service-learning (CSL) is increasingly seen as an educational approach that can enhance student engagement and serve community needs. However, CSL programs are highly variable in their structures and goals, leading to variability in the outcomes sought and attained. In this paper, we map out the structures and priorities of CSL programs in Canada following a major influx of funding from the McConnell Family Foundation grant competition in 2004. We also contrast key features of these programs, including their institutional location, unit organization, and educational delivery approach, in order to demonstrate the potential implications of different program models. Our aim is to offer new and developing programs some guidance on the program structures that have been employed as well as their implications.
\end{abstract}

KEYWords CSL programs, institutional differences, Canada

\section{Introduction}

According to the Canadian Alliance for Community Service-Learning (CACSL), "Community Service-Learning (CSL) is an educational approach that integrates service in the community with intentional learning activities" ("What is CSL?" n.d). With reciprocity as one of its key principles, CSL is most effective when members of educational institutions and community organizations work together toward outcomes that are mutually beneficial. CSL is increasingly recognized as a priority for post-secondary institutions interested in student engagement (Kuh et al., 2010; Lenton et al., 2014; Longo \& Gibson, 2011). At least fifty campuses in Canada had service-learning programs in 2010 (Keshen, Holland, \& Moely, 2010), and this has continued to grow as universities seek to expand their engagement with community. However, these programs are highly variable in terms of how they are structured and the work that they prioritize, often leading to very different outcomes.

Moreover, Canadian service-learning lacks the coordination evident in the United States, where it has been supported by various levels of government, receives institutional and foundation funding, and has dedicated conferences and academic journals (Aujla \& Hamm, this issue; Raddon \& Harrison, 2015). Instead, CSL growth in Canada has been spurred partly by non-governmental players and has taken different forms. Following a Call for Proposals in 2004, the J.W. McConnell Family Foundation (hereafter referred to as McConnell) granted 
$\$ 9,400,000$ to ten Canadian Universities to support the development and expansion of CSL (almost \$1,000,000 each over five years) under its National University-Based Community Service-Learning Initiative ("CSL Awards," n.d.).

In an effort to support CSL programs still under development today, in this paper we offer a snapshot of the diverse Canadian CSL programs that were stimulated by McConnell funding. These programs differ in terms of their institutional location, unit organization (including staffing model and funding sources), and educational approach. We hope that this discussion will encourage CSL advocates to design or further develop programs that support their intentions and fit their unique contexts. We begin by briefly describing key characteristics of each of the nine CSL programs in this study, as they were at the time of data collection. We then discuss programs that exemplify some of the differences across the country and consider implications of differences in local contexts (including regional and cultural differences) for a national movement around CSL in Canada.

\section{Methods}

This essay adopts a descriptive qualitative approach (Sandelowski, 2000, 2010) by providing a brief description of CSL programs that successfully applied for and received McConnell funding to develop or expand their CSL programs and making comparisons between these descriptions. ${ }^{1}$ Since programs change over time, this paper provides a snapshot during the period immediately following the completion of McConnell funding. This was an important milestone in the development of programs at these universities because it involved the transition from McConnell funding to other sources and discussions about institutionalizing these programs (Taylor \& Kahlke, 2017).

We used three main sources of data to develop these descriptions: first, semi-structured qualitative interviews were conducted between 2012 and 2013 with fifteen key program administrators from nine of the ten McConnell-funded programs and two national-level representatives (one from the McConnell foundation, the other from the Canadian Alliance for Community Service-Learning). Initially, we identified program leads from each program's website. Following initial interviews, a snowball sampling approach (Atkinson \& Flint, 2001) was used to identify additional informants, such as former directors, for their ability to comment on the development and structure of each program. The original study for which these data were collected examined how CSL administrators, instructors, and community partners understand their work. Institutional ethics approval for this study was obtained through the University of Alberta. The second data source was content provided in public websites for each program. Third, we examined available publications and reports published by administrators of each program and by the McConnell Foundation. Details about programs in different universities were returned to participants to confirm accuracy, but only three of the fifteen responded with changes, which were incorporated. Since programs change over time, this paper provides a snapshot during the period immediately following the completion of McConnell funding.

\footnotetext{
${ }^{1}$ The CACSL website includes the successful proposals from universities.
} 


\section{Results}

In this section, we begin by providing information about the McConnell granting program and the CSL programs it funded. The overview of CSL programs reveals notable differences in the structures, goals, and educational delivery approaches between McConnell-funded programs. Following the overview, we focus on pairs of universities to address some key areas of difference, including institutional structures such as staffing, funding, and institutional location; the organization of CSL units within universities; and CSL delivery models, such as course-based CSL or co-curricular CSL. ${ }^{2}$ We then consider the implications of these local distinctions for the larger CSL movement in Canada.

\section{The J.W. McConnell Family Foundation}

McConnell's CSL program was initiated with the belief that positive benefits would result if universities and communities combined "knowledge, experience, and commitment to tackle local issues" (Cameron, 2010, p. 5). Through its funding program, the McConnell Foundation played an important role in shaping the aims of programs in Canadian universities:

[A]s it was framed in the original letter from the Foundation, there were clearly three parts to it. One was, of course, enriching the experience of students through a handson experiential process. Two was having positive impact on the ability of community organizations to achieve their goals. The third one, which in a way was the sleeper, was to what extent could the lessons of CSL actually come back to the mother ship and in some cases challenge or influence both the content and pedagogy of the university? (Interview 7)

A letter to universities from the McConnell program officer reflecting on the activities of funded universities suggested some frustration with the pressure placed by university administrators on expanding "CSL programs as quickly as possible" (Cawley, 2007). The perceived emphasis on quantity over quality was seen as impeding the achievement of aims set out by McConnell for the program. Of course, not all university programs followed the same path, and the diversity of programs is presented below; McConnell's message was interpreted differently in different local university and community contexts.

\section{Overview of institutions}

This section offers a brief description of each of the nine programs in this study. We then relate notable characteristics of each at the time of interviews in 2012 to 2013, ${ }^{3}$ including funding sources, staffing, type(s) of CSL programming offered, and location within the University. As discussed in a later section, location within the University impacts how others perceive units and how units perceive themselves. Generally, CSL units fall under a Vice-President

\footnotetext{
${ }^{2}$ Curricular programs integrate CSL activities within existing academic curricula while co-curricular programs offer volunteer experiences that are not recognized through academic credits.

${ }^{3}$ We use the present tense to discuss programs, recognizing that changes have no doubt occurred since the time of interviews. As noted, this essay is intended to provide a snapshot at a point in time.
} 
(VP) Research, Academic, or Student Affairs portfolio. These portfolios do vary somewhat between institutions; ${ }^{4}$ however, most institutions have a senior administrator, usually reporting to the president, in charge of each of the institution's three main areas: research, teaching (also referred to as "academic"), and student services (student life and academic support services), respectively.

\section{St. Francis Xavier University}

St. Francis Xavier University (St. FX) is one of the earliest CSL programs in Canada; it received funding from the McConnell Foundation prior to the Foundation's formal call for proposals for CSL (Cameron, 2010). St. FX has a long social justice tradition and is home to the Coady International Institute, named for Moses Coady, an adult educator and social justice activist (Welton, 2006). Not surprisingly, CSL administrators at St. FX also claim a social justice focus for their work.

CSL at St. FX was modelled after a program at a small U.S. college and takes two distinct forms, curricular (integrated within courses) and immersive, mostly international experiences. The CSL unit falls under the VP Academic (i.e. teaching) portfolio and is supported primarily through core funding from the University as well as some private donations. CSL at St. FX is deeply embedded in the small rural community of Antigonish, Nova Scotia, but also participates in international CSL, connecting students to communities all over the world.

\section{Lakehead University}

Lakehead University, located in Thunder Bay, Ontario, provides a unique CSL model in the form of the Food Security Research Network. This model focuses all CSL activities on issues of food security, an area of specialization for Lakehead and an issue of importance in the geographically isolated communities of northern Ontario. The food security focus is also important to the Indigenous communities in the region, who face issues related to food security stemming from changes to traditional lands and food sources.

Lakehead is also unique in viewing research, teaching, and service as integrated activities. Founded by Lakehead's former Vice-President of Research and initially funded by McConnell, the Food Security Research Network fell under the VP Research portfolio. It received some core funding from the University, but was also funded through various research, government, and private grants. Lakehead decided to employ only a very small contingent of permanent staff, instead hiring graduate students to assist in its research and teaching initiatives. Faculty members engaging in CSL are encouraged to integrate their teaching, research, and community partnerships; as a result, CSL at Lakehead engages proportionately more senior faculty members and fewer students (but proportionately more graduate students) than most other McConnellfunded programs. CSL delivery often focuses on interdisciplinary collaborations around food security and is project-based, as opposed to CSL that involves placement activities (including day-to-day operating tasks) within the community organization. At Lakehead, project-based

\footnotetext{
${ }^{4}$ For example, the University of Alberta has a Dean of Students, rather than a VP Students or a VP Student Affairs.
} 
CSL is curricular and engages students in completing a project intended to be useful both to the community partner and to the students' learning.

\section{Université du Québec à Trois-Rivières (University of Quebec at Trois Rivieres)}

In an area of the country that has suffered from deindustrialization, high unemployment, and the out-migration of youth (Cameron, 2010), Trois-Rivières Projet d'Intervention dans la Communauté (Picom) focuses on several main themes called "Carrefour" or, in English, "intersections," which are geared toward the needs of the community. Examples include the Écol'Hôtel, a boutique hotel designed, managed, and marketed by students in the postsecondary institutions in the region; Santé Global, a community health clinic; and Plein Air de Joie, a camp for people with disabilities. All of these projects are designed to contribute to the social economy by reinvesting in the region in some way (Cameron, 2010).

CSL is deeply embedded in the Trois-Rivières community and many of the above social enterprises are collaborations with government and other post-secondary institutions in the region. Since McConnell funding ended, funding comes from a blend of university, government (including research grants), and private foundations. Like the Lakehead University model, CSL delivery is project-based, and students can engage in it as part of a large interdisciplinary project or within a disciplinary course.

\section{Nipissing University}

Nipissing University's Biidaaban ${ }^{5}$ Community Service-Learning (BCSL) program is distinctive in its Indigenous focus. Like the program at Lakehead, this program reflects its northern Ontario context. It is housed within Aboriginal Initiatives and grew out of the Director's efforts "to develop or expand existing support services for Aboriginal students, trying to expand their participation in undergraduate studies." This has meant a significant focus on developing programming to support Indigenous youth in the area.

Aboriginal Initiatives falls under the unique combined portfolio of the Vice-President Academic and Research. It receives some core funding for staff salaries from the university, but also seeks funding from a variety of sources, including smaller foundations and provincial funding initiatives. CSL delivery occurs through community placements that can be incorporated as an assignment in existing courses and are mandatory for students enrolled in the Consecutive Education and Bachelor of Physical Health and Education degree program. Most placements take place in schools or after-school programs.

\section{University of British Columbia (UBC)}

UBC's CSL programming began as a co-curricular program led by the Learning Exchange that engaged UBC students with Vancouver's economically troubled downtown eastside community. Over time, UBC developed two separate units that provide off-campus opportunities for students: the Learning Exchange (located in and focused on issues related to the downtown

\footnotetext{
${ }^{5}$ Biidibaan (Ojibwe word) refers to the point at which the light touches the earth at the break of dawn.
} 
eastside) and the Community Learning Initiative (located on the UBC campus and focused on the broader community). The latter, later called the Centre for Community Engaged Learning, offers both co-curricular (Trek program, Reading Week placements) and curricular servicelearning.

At the time of our interview, the Learning Exchange fell under the VP External portfolio, while the Centre fell under Student Services and reported to the VP Students. UBC was one of the few institutions to have increased its funding since the end of the McConnell grant through combined university funding and large donations from corporations such as HSBC and Telus. The Learning Exchange also actively seeks funding from private donations. Reflecting these resources, the Centre for Community Engaged Learning has had a relatively large staff, including a director and three managers focussed on the university side of CSL, the community side, and research/program evaluation, respectively. The team also included eight staff coordinators and administrators, three graduate research assistants, and four part-time staff coordinators housed in different faculties at the time of interviews. However, corporate funding was for a fixed term, raising questions about sustainable growth in programs. ${ }^{6}$

\section{Trent University}

The CSL program in Peterborough is particularly unique in its institutional location. Like UBC's Learning Exchange, the Trent Centre for Community-Based Education (TCCBE), which was founded in 1996 and renamed the Trent Community Research Centre in 2015, is physically separated from the Trent University campus, located in downtown Peterborough. Further, TCCBE holds registered charity status and works with other post-secondary institutions in the area beside Trent University, primarily Fleming College. In the director's words, "we're place-based as opposed to institution-based, which I think is to everyone's advantage." The Trent Centre also works closely with and administers funding for the U-Links Centre for Community-Based Research in Haliburton County. The current website suggests the Trent Community Research Centre facilitates the matching of students and faculty with community research projects that may be part of a course or co-curricular.

At the time of interviews, the Trent Centre fell under various VP portfolios at Trent University, working with the VP Advancement and External Relations, the VP Research, the VP Students, and directly with the Provost. Also, despite its separation from Trent University, much of the Trent Centre funding came from there. However, the Trent Centre has been partially funded through diverse external sources, too, including federal and provincial government sources, private and public foundations, individual donors, and fee-for-service approaches. The Trent Centre offers three types of curricular project-based CSL: 1) community-based education projects that are four to eight months in length, generally structured around the academic term, and generally involve capstone undergraduate experiences, 2) community service-learning, involving ten to twenty hour projects linked to courses, and 3) strategic

\footnotetext{
${ }^{6}$ In fact, some of the corporate funding recently ended and there have been staffing reductions, which indicates the uncertainty for programs that comes along with reliance on this kind of funding.
} 
research initiatives, which are paid community research assistantships within existing faculty research programs.

\section{University of Alberta ( $U$ of $A$ )}

CSL began in the Faculty of Arts at the initiative of a faculty member before the application for McConnell funding was made. As a result, CSL at the U of A has been predominantly taken up by instructors in this faculty and is grounded in social justice issues that provide a focal point for the work of this faculty. The $U$ of $A$ program provides an embedded certificate (a certificate in Community Engagement and Service Learning, which can be part of undergraduate programs offered across the university); as part of this certificate, a small number of CSL-designated courses focused on community-engaged learning are offered. One of these courses took the oil economy as its theme for several years, reflecting issues resulting from the "boom and bust" Alberta economy.

Over time, CSL has expanded to more faculties, but remains housed in the Faculty of Arts, reporting to the Dean's office at the main campus and in the Learning, Advising and Beyond Office at Augustana campus. The Faculty of Arts funds the program with some support from central administration, as well as from private donations. The CSL office at this university is also unique in that it includes Humanities 101, an outreach program designed to provide university-style education to learners in the community who are living with poverty, homelessness, violence, and health issues. The $\mathrm{U}$ of $\mathrm{A}$ is primarily engaged in curricular servicelearning and its Augustana campus program provides some international CSL opportunities.

\section{Wilfred Laurier University (WLU)}

Wilfred Laurier University's (WLU) CSL work, like the U of A, developed out of its inception in a particular faculty; at WLU, this was a large, long-running field placement program in Developmental Psychology, Faculty of Science. This field placement program was re-imagined using the CSL goal of providing mutual benefit to the community and university. WLU's program continues to have a strong focus in Psychology but, like the $\mathrm{U}$ of $\mathrm{A}$, has branched out to other faculties and departments since its inception. Sign-up for the Psychology program takes place through a large database of community placements developed through McConnell funding.

Unlike the U of A, however, CSL at WLU did not remain in its home faculty, but moved to Student Services. Recently, it relocated under the Centre for Teaching Innovation and Excellence, within the VP Academic portfolio. WLU's program has a relatively small staff supported by paid teaching assistants (TAs). Core funding is provided by the central administration. The program runs primarily undergraduate curricular CSL and can be either placement-based, as it is for the large Developmental Psychology cohort, or project-based. Perhaps because of its roots in student services, WLU's CSL program also runs a co-curricular volunteer program. 


\section{University of Ottawa ( $U$ of $O)$}

The University of Ottawa (U of O) CSL program was initiated through a partnership between professors in History and Law interested in applying for McConnell funding. Although the Environmental Law Clinic built into the original proposal still exists, the CSL Program at U of $\mathrm{O}$ is implemented across eight faculties and is housed within the Centre for Global and Community Engagement, now called the Michaëlle Jean Centre for Global and Community Engagement. The Centre was created in 2010 as part of the University's Destination 2020 strategic plan. Initially, CSL was housed under the Student Academic Success Services, but later moved into the Centre for Global and Community Engagement. Its mandate is to promote community engagement and social responsibility among its students. The Centre organizes or facilitates curricular, co-curricular, multi-year, and international community service projects. The Centre mainly works with the non-profit sector, charities, and social enterprises.

The Centre reports to the Associate VP Students Affairs. The CGCE is funded through a combination of core funding from the University and various sources of external funding, including grants, individuals, and foundations. It was staffed by eight full-time employees at the time of interviews.

\section{Comparing CSL Programs}

An analysis of the structure and foci of CSL units reveals similarities and differences across McConnell-funded programs. While some of this variability can be traced to the unique interests and skills of CSL founders and leaders, CSL units are also tied to the distinct contexts in which they function. The next section of this paper looks more closely at issues of institutional location, unit organization, and CSL delivery approach; in each section, we have selected two institutions which provide a comparison of factors that reflect the local contexts in which CSL units are embedded.

\section{Institutional location: Trent and Lakebead}

A "scan" of CSL programs in 39 universities and three colleges across Canada found that CSL units have different names and locations across institutions (Baloy, 2014), confirmed also in our study of McConnell-funded programs. Kezar and Rhoads (2001) suggest service-learning programs challenge existing divisions within universities, for example, between formal and informal learning, and between research, teaching, and service. CSL does not fit neatly into a single portfolio. The institutional location has far-reaching implications for the work of CSL administrators, though was not always a result of strategic planning. For example, a few of our participants confirm Kezar and Rhoads's (2001) observation that CSL may lack perceived legitimacy when it is housed in Student Affairs. Reporting to central administration may provide greater access to resources while a location within a faculty may enhance legitimacy within the university. Besides legitimacy, a lack of direct connection to faculties, including input into decisions about programs and discussions about the scholarship of teaching, is likely to limit the effectiveness of CSL programs. This section looks at two cases where CSL has been intentionally and uniquely located: the Trent Centre for Community-Based Research 
and Lakehead's Food Security Network.

As noted above, the Trent Centre for Community-Based Research is supported by Trent University but operates as a separate entity brokering relationships between community and post-secondary institutions. The Centre focuses heavily on collaboration and maintaining a focus on community needs. In the words of a representative:

I think one of our strengths is that we think of community from that perspective. We think about it in terms of issues ... it's coming at it from a community perspective and also from a collaboration point of view, from a win-win point of view. (Interview 4)

In this sense, the institutional location of the Centre has broader philosophical underpinnings based on a focus on community needs and mutual benefit that is embedded in the institutional location.

An additional, related advantage of the Centre's non-profit status is its freedom to partner with multiple institutions, in keeping with its mission of serving the community. According to the Executive Director:

Because we're a non-profit we're not tied to one institution, which is one of the advantages of the model. We're place-based as opposed to institution-based, which I think is to everyone's advantage. That's the way I frame it for everyone. (Interview 4)

The Trent Centre is thus able to focus primarily on the needs of community, drawing on learners from multiple post-secondary institutions whose knowledge, skills, and availability match those needs.

Like Trent, Lakehead University has shaped its institutional location with intention and with the needs of the community in mind. Lakehead's unique institutional location, reporting directly to the VP Research, and lacking affiliation with a specific faculty, allows the unit to bring together individuals across disciplines around common research interests. According to the Director:

I purposely did that and was able to negotiate that through the system because that gives me as the Director the most flexibility. I didn't want to get engaged in the quagmire of deciding who owns CSL and getting into all these arguments with the deans. (Interview 13)

This freedom led to a deliberate focus on the community issue of food security. This focus was identified by the founder as a timely and relevant issue for the northern communities in and around Thunder Bay, which are concerned about changes to the traditional harvesting practices of Indigenous groups, as well as the cost of food transportation to and from these communities and other regions: 
This thematic focus was intended to build rich partnerships based on a common interest: Reading the literature, one of the things I didn't want to happen is I think it's so easy
for CSL to potentially perpetuate the "us" and "them" mentality that we are university
students and we are going to go out and work with these poor community groups
and we're going to give them something that they don't have because they're not in
university. I didn't want that to happen; I wanted it to be equal. (Interview 13)

In the partnership, the community offers particular knowledge and expertise, with community partners acting as co-educators and co-researchers, rather than as subjects for the application of the knowledge that students obtain in the university or for the extraction of data to meet a researcher's needs. Like Trent, Lakehead seeks to build partnerships based on mutual benefit. The integration of community-based research (CBR) and community service-learning (CSL) is relatively unique among the institutions in our study since CBR does not necessarily involve students and CSL does not necessarily involve research. In the case of Lakehead's network, there is deliberate overlap in these practices.

The focus on food security, combined with the integration of community-based research and teaching, has several advantages. First, the integration of teaching and research might be seen as better meeting community needs, which are complex and often require both human resources and research expertise:

Because we're in the research end ... we don't see it as siloed. One thing leads to the other, where we feel very free. We feel that we are in community too, that we're part of this community. (Interview 13)

Additionally, Lakehead's marriage of CBR and CSL interests around the issue of food security seeks to address a common problem experienced by other CSL programs: community groups feel bombarded by too many requests for partnership from too many different sectors of the university. Lakehead's focus on projects rather than placements is an attempt to reduce community partner fatigue by emphasizing project products that will be of use to community partners. According to the Director:

I was looking at something that would counter this comment that had begun to surface in 2005 that CSL can exhaust the community. . . . It's certainly pro for the community, as we don't exhaust the community. They are engaged in CSL because they've got something to genuinely contribute and they're really interested in the results. (Interview 13)

Likewise, the combination of teaching and research interests has engaged more senior faculty in CSL work. In other sites, sessional or teaching-stream faculty tend to undertake CSL more often then senior faculty.

The examples of Lakehead and Trent are unique because of their emphasis on community- 
based research and project-based as opposed to placement-based service-learning. There are a few implications worth mentioning: first, these models attempt to prioritize community over university in the development of projects, and, perhaps as a result, seem to pay less attention to growth in student numbers as their main metric. Community impact is, in theory, more central to program decisions. Second, involving students in community-based research blurs the boundaries between teaching and research (cf. Kezar and Rhoads, 2001). Finally, legitimacy tends to be enhanced when CSL programs are associated with research, which is generally seen as the raison d'être of universities.

\section{The organization of units and work: $U B C$ and Wilfrid Laurier}

Aside from Trent University, McConnell-funded universities had units centralized within the university that coordinated CSL. ${ }^{7}$ While it would be interesting to compare programs in universities with a centralized unit to those without one, that is beyond the scope of this study. One might assume that institutions without a centralized unit would experience more internal variation in CSL because such a unit is likely to promote greater consistency if it provides support and guidelines to instructors as part of its mandate (e.g., defining CSL as a 20-hour placement, providing tips for effective CSL, etc.).

Looking at the McConnell universities with a central unit made it clear that the organization of these units varied. They had varying levels of core funding and different staffing arrangements. While some employed permanent full-time staff, other units relied more on part-time employees and temporary graduate student assistants, sometimes because of a lack of core funding. Clearly, the number and type of staff have implications for the type and range of possible activities and the legitimacy and sustainability of the program. This section examines two contrasting programs. UBC's Centre for Community Engaged Learning had received significant private and internal funding at the time of our interviews, allowing it to employ a relatively large full-time staff. Wilfrid Laurier University's program, on the other hand, had a much larger staff-to-student ratio.

Despite some variability from year to year, UBC's program was funded primarily through substantial ongoing commitments from the university's central administration and from HSBC bank. ${ }^{8}$ As a result of this funding, UBC's Centre for Community-Engaged Learning was run on a hub and spoke model. The "hub" or central unit employed a large staff, divided into three functional units overseen by a director. The community-based experiential learning team was comprised of a manager and team of five staff, focusing on curricular CSL. The community-based partnership team included a manager and team of four staff, focussed on the community side of engagement. The research and evaluation team was led by a manager and staffed through several graduate research assistants. The "spokes" supported CSL development in the faculties through the work of four parttime staff members who served as CSL advocates in different faculties. Instructors were

\footnotetext{
7 The U of A unit is "centralized" within the Faculty of Arts as opposed to the university as a whole.

${ }^{8}$ Note that HSBC funding has now ended at UBC and staffing has been adversely affected.
} 
expected to play a key role in working with community partners while CSL staff helped match instructors with community partners and provided pedagogical support.

The program at Wilfrid Laurier University provides an interesting contrast:

We're short on staff. If you compare our budget or our size of program to UBC's ...they've got a staff of 30 and they're working with 2,000 students. Our budget is $\$ 300,000$ and a staff of four with 2,000 students. ${ }^{9}$ (Interview 8)

Although the full-time staff complement at UBC is smaller than suggested above (16 at the time of our interview), it was still more than four times the complement at WLU, while working with a similar number of students. More than one third of the students at WLU were in large psychology classes, which resulted in a different approach to CSL; for example, approximately 600 students a year in these classes signed up online for placements. Representatives from the WLU CSL unit discussed the unit's early focus on quantity of CSL placements as related to the initial focus on large psychology classes and the perception that accountability metrics for McConnell funding should focus primarily on student numbers. The lack of staff resources to accommodate the large numbers resulted in the need to use technology to efficiently match students to community placements. But, in this case, an online sign-up system used to manage these large student numbers with few staff resulted in student anonymity and potential mismatch with community partners, according to program representatives. The program leader at the time felt the focus on numbers promoted an approach to service-learning that was more transactional than transformational for all participants (students, instructors, and community partners).

In sum, the examples above suggest different approaches to determining the scope of CSL work and its organization, including the roles of different participants. The servicelearning staff-to-student ratio, the degree to which student numbers were seen as the dominant metric, and the types of relationships between CSL staff, students, instructors, and community partners varied across universities. Although not discussed in the examples of UBC and WLU, program leadership (e.g., non-academic or academic staff) also has implications for how programs are conceived and structured. All of these program decisions, which are related to aims and resources, have clear implications for the ability of universities to develop programs rooted in knowledge about effective pedagogy and based on high-quality, mutually beneficial, and sustainable partnerships.

\section{Educational delivery: University of Ottawa and University of Quebec at Trois-Rivières} The philosophical orientations of CSL across institutions-for example, along a continuum of critical to traditional approaches (cf. Mitchell, 2008; Chambers, 2009)—were not always evident at a program level. However, choices around how CSL is delivered on campuses were clearer. CSL programs across Canada utilize various delivery approaches including curricular

\footnotetext{
${ }^{9}$ Two of the staff members at Wilfrid Laurier University were part time coordinators (26 hours/week) on 8-and 10-month contracts.
}

Engaged Scholar Journal: Community-Engaged Research, Teaching, and Learning 
service-learning (CSL placements or projects embedded in existing courses or programs); cocurricular CSL (placements or projects done on a volunteer basis outside of a course); and international CSL (an experience in another country that can be either project or placement based, curricular or co-curricular). While curricular service-learning necessarily prioritizes the integration of community learning with students' formal coursework, co-curricular CSL may be less constrained by formal learning objectives and may allow for more sustained engagement. International service-learning (ISL) encourages the development of global citizenship while, in our data, CSL tends to be concerned with development of their local community. Program choices are, of course, related to previously discussed factors such as the number and type of staff and the location of CSL within the university as well as regional differences and aims.

The universities of Ottawa and Quebec at Trois-Rivières offer different approaches that partly reflect their distinct locations and aims; this discussion focuses on differences in the aims, scope, and delivery of programs. The program at University of Quebec at Trois-Rivières involves fewer students with a focus on a small number of large, long-term projects, while the program at the University of Ottawa offers a range of service-learning opportunities to over 2,000 students.

The program at University of Ottawa, originally modeled after programs in the United States, involves curricular CSL across the university in which students engage in 30-hour placements:

I think 2,000 will be the total number of volunteer placements in courses that we will facilitate each year unless we get more funding. We just signed up with the Faculty of Medicine and we're going to take on 165 students in first year to give a specific CSL course. The CSL program is for the most part voluntary. Very few professors make it mandatory. We're in seven faculties out of ten.

The aim of the CSL program at the University of Ottawa was to involve ten percent of the full-time student population annually, according to its proposal to McConnell ("Communities as Classrooms," 2005). In addition to curricular CSL, which involved 160 courses (mostly undergraduate) at the time of our interview, the Centre for Global and Community Engagement coordinates international student engagement opportunities. Most CSL placements involve notfor-profit and government organizations as community partners. Students' CSL experiences are tracked on a co-curricular record which indicates the number of volunteer hours, whether they were part of a course for credit or not, and the type of placement. The role of staff is to provide outreach to professors, answer questions from students and community partners, and build relationships. The University of Ottawa program balances more formal curricular CSL with co-curricular placements — a unique approach among universities within this study. This "full service" approach potentially allows for greater ability to meet the needs of community partners, which do not usually fit neatly into the university calendar and schedule.

Even more emphasis on community development is evident in the rural context of University of Quebec at Trois Rivières, where one full-time and two part-time staff work on 
establishing university-community connections and large-scale projects that, at the time of our interview, involved approximately 300 students:

The [full-time] coordinator [who has experience in the community] makes the connection between community groups and faculty. But for the community-university intersections [i.e., the specific social enterprises mentioned earlier], we are three who are working on that. But like me, I work part-time on community university intersections.

The staff works towards facilitating a small number of long-term community-driven projects that allow students to engage for longer periods of time-for example, a camp for people with disabilities (Plein Air de Joie) and other examples listed above. Given that the region has suffered from de-industrialization and the out-migration of youth, it is not surprising that community development and social enterprise are priorities. According to one program representative,

[A longer project] gives the advantage for the students. It gives them more involvement, more experience, more knowledge from the community organizations. They have to understand what is the need of the community organization; it takes time. They have to understand the culture of the community organization; it takes time. After, when they understand, then they can build their project. It can be in one semester or two semesters. ... we want always that the students are doing something for the community. They give something to the community organization-work or a tool that will be useful.

The "intersections" are also unique in that they are not strictly non-profit initiatives; many, such as the Écol'Hôtel, are designed to turn a profit and to reinvest that profit in the community: "we work to help the organization to develop social economy enterprise, [which] means that we want [to] develop services for people who have money but with the profits it will be reinvested in the social mission. We call that the Robin Hood system.” Students engage with the Projet d'Intervention dans la Communauté either through a broad interdisciplinary course, called an "institutional course," or through a smaller disciplinary experience, embedded in more traditional existing course infrastructure. The approach adopted in Trois Rivières is curricular, but also uniquely embedded in its community.

The University of Ottawa, on the other hand, is in an urban context in a city largely dominated by the public sector. Their proposal to the McConnell Foundation focused on developing CSL in particular faculties_LLaw and Health Sciences. The proposal makes it clear that plans for CSL are impacted by the academic areas of strength in the university as well as the type of community partners and issues in the city and region:

This proposal has outlined the University's specific strategies for leveraging its strength as a knowledge producer to benefit community organizations, such as: . . . developing new intensive CSL programs aimed at high-need issues in the National Capital Region

Engaged Scholar Journal: Community-Engaged Research, Teaching, and Learning 
in which the University has great strength (environment and health).

In sum, the differences in approach described above no doubt reflect characteristics unique to different parts of the country that impact the development of CSL programs in those locations, such as characteristics of local post-secondary institution(s), geographic location (including whether the PSE is more urban or rural), and other aspects of local culture.

\section{Discussion}

The preceding overview and examples suggest that CSL programs at McConnell-funded universities have developed in ways that reflect their university and community contexts, individual leaders, resources, and institutional locations. For that reason, it is difficult to talk about a national approach or movement around CSL in Canada. It is evident that, particularly in more rural settings, CSL programs seem to take up community issues in a more directed and targeted way - for example, Lakehead University's focus on food security and Nipissing's focus on Indigenous student attainment. At the same time, the backgrounds of leaders also play a key role; leadership from a former administrator at Lakehead led to more research-focused CSL, while at Wilfred Laurier, CSL's beginnings in large psychology classes led to an emphasis on the quantity of placements and a technology-focused approach to managing student numbers. In some cases, programs had already begun in nascent forms prior to McConnell funding, and those in existing CSL leadership roles were thus key players in the funding applications and subsequent shaping of programs.

In addition, as noted above, the McConnell Foundation played a role in shaping programs. In addition to its funding program, it hosted meetings to share ideas across funded universities and also established CACSL to do this more broadly via conferences, a website with resources, and so on. But the ability of CACSL to play a significant role in a national CSL movement has been limited by its lack of resources as well as the unique development of programs in very different contexts. ${ }^{10}$ Just as other areas of Canadian policy have been impacted by provincialfederal jurisdictional tensions and regional differences, CSL reflects these realities.

Although McConnell's aim of changing universities in substantial ways was probably not realized, their provision of significant seed funding was important in developing and expanding CSL programs in ten universities. Most institutions were able to maintain and some expanded their staff complement, number of students, courses, and community partners through a combination of university and private support at the end of the five-year McConnell funding. On the other hand, a few were satisfied with their small size, focusing on providing more intensive community-based experiences and building deep relationships with community. These choices about unit organization, staffing, and funding reflect many contextual factors, including the size of universities, whether they are research or teaching intensive, backgrounds of program leaders, and community context (e.g. rural vs. urban).

\footnotetext{
${ }^{10}$ At this time of publication, CACSL is inactive and without leadership (see information provided by Dr. David Peacock in the introduction to this issue); the role the alliance will play moving forward in CSL in Canada is therefore difficult to predict.
} 
As suggested above, the question of growth was relevant for most participants. It was clear that some CSL leaders felt significant pressure from university administration and perceived McConnell Foundation expectations to involve large numbers of students from the start. But McConnell did not actually require reporting of numbers; in fact, a letter written by a program officer to the Canadian Alliance for Community Service-Learning (Cawley, 2007) suggested that grant recipients should give greater attention to community impact and not just "outputs" (e.g., number of students and courses). Over time, patterns and relationships with internal and external partners became institutionalized. For example, programs with the initial aim of including as many students as possible in CSL were unlikely to suddenly cut their numbers drastically, even when funding ended. In addition, as programs became more embedded in structures, universities began to compare themselves with one another (particularly those of a similar size) and engage in isomorphic practices around what they saw as "best practices" (DiMaggio and Powell, 1986).

\section{Conclusions}

Both unique and common contextual factors have impacted how CSL programs have developed within a group of Canadian universities. It is evident that the organization of programs (institutional location, unit organization, and delivery mechanisms) impacts and is impacted by the founders, contexts, and type of programs. The number and type of staff (e.g., academic or administrative, part-time/full-time, level of position), institutional location of programs (e.g. in student service units, faculties, or research centres), and the delivery of programs (e.g., curricular, co-curricular, international) are interrelated and have important implications for the program as a whole. To this point, programs have evolved in quite distinct ways, despite the common influence of McConnell funding. Differences in region, culture, and university size have affected the trajectory of CSL in Canadian higher education, and, unlike in the United States, the lack of governmental involvement has also made it difficult to talk about a national approach. In our view, this is not problematic. More importantly, as CSL programs continue to be established and evolve at Canadian universities and colleges, discussions are needed about how the range of internal and external factors should be taken into account in decisions about CSL program aims, structures, and outcomes in different sites.

\section{Acknowledgements}

Alison Taylor acknowledges funding support for this project from a Killam cornerstone grant at the University of Alberta and from Social Sciences and Humanities Research Council funding. Thank you also to all of our participants and to Zane Hamm who worked as a research assistant in collecting some of the data for this study. 


\section{About the Authors}

Renate Kahlke (corresponding author) is Postdoctoral Fellow at the Centre for Health Education Scholarship and Department of Medicine, University of British Columbia. This paper was supported by a Research Assistantship at the Department of Educational Policy Studies, University of Alberta. Renate is an educational researcher focussed on the application of knowledge in practice for health professionals. Email: rkahlke@royalcollege.ca

Alison Taylor is Professor in Educational Studies, University of British Columbia. Her current SSHRC-funded research focuses on students' CSL experiences at two Canadian universities. Related writings have been published in the Canadian Journal of Higher Education, Vocations and Learning and the forthcoming book, Handbook of Service-Learning for Social Justice (Wiley).

\section{References}

Atkinson, R., \& Flint, J. (2001). Accessing hidden and hard-to-reach populations: snowball research strategies. Social Research Update, 33. Retrieved from http://sru.soc.surrey.ac.uk/SRU33.html

Baloy, N. (2014). Canadian scan highlights guide. Unpublished document, Centre for Community Engaged Learning. Vancouver, BC: University of British Columbia.

Bringle, R., \& Hatcher, J. (2000). Institutionalization of service learning in higher education. The Journal of Higher Education, 71(3): 271-290.

Cawley, J. (2007). Community service-learning: Reflections for the foundation.

Cameron, S. D. (2010). Getting wisdom: The transformative power of community service-learning.

Canadian Alliance for Community Service-Learning. (2006). Community service-learning in Canada:

A scan of the field. Guelph, ON: Canadian Association for Community Service Learning.

Canadian Alliance for Community Service-Learning. (n.d.). Community service-learning in Canada.

Canadian Alliance for Community Service-Learning. (n.d.). What is CSL?

Chambers, T. (2009). A continuum of approaches to service-learning within Canadian postsecondary education. Canadian Journal of Higher Education, 39(2): 77-100.

DiMaggio, P., \& Powell, W. (1983). The iron cage revisited. American Sociological Review, 48(2): 147-160.

The J.W. McConnell Family Foundation. (n.d.). CSL awards. Retrieved from http://www. mcconnellfoundation.ca/en/programs/community-service-learning/csl-awards

Keshen, J., Holland, B. A., \& Moely, B. E. (2010). Research for what?: Making engaged scholarship matter. Charlotte, NC: Information Age Publishing.

Kezar, A., \& Rhoads, R. (2001). The dynamic tensions of service learning in higher education. The Journal of Higher Education, 72(2), 148-171.

Kuh, G. D., Kinzie, J., Schuh, J. H., Whitt, E. J., \& Associates. (2010). Student success in college: Creating conditions that matter. San Francisco, CA: Jossey-Bass. 
Lenton, R., Sidhu, R., Kaur, S., Conrad, M., Kennedy, B., Munro, Y., \& Smith, R. (2014). Community service learning and community-based learning as approaches to enhancing University service learning. Toronto, ON: Higher Education Quality Council of Ontario.

Longo, N., \& Gibson, C. (Eds). (2011). From command to community: A new approach to leadership education in colleges and universities. Medford, OR: Tufts University Press.

Mitchell, T. (Spring 2008). Traditional vs. critical service-learning: Engaging the literature to differentiate two models. Michigan Journal of Community Service Learning, 14(2), 50-65.

Raddon, M., \& Harrison, B. (2015). Is service-learning the kind face of the neo-liberal university? Canadian Journal of Higher Education, 45(2), 134-153.

Sandelowski, M. (2000). Whatever happened to qualitative description? Research in Nursing and Health, 23, 334-340.

Sandelowski, M. (2010). What's in a name? Qualitative description revisited. Research in Nursing and Health, 33, 77-84. doi:10.1002/nur.20362

Taylor, A., \& Kahkle, R. (2017). Institutional logics and community service-learning in higher education. Canadian Journal of Higher Education, 47(1), 137-152.

Trent Community Research Centre. (n.d.).

University of Ottawa. (2005). Communities as classrooms: A proposal to expand the depth and breadth of CSL in Canada's capital. Retrieved from http://www.communityservicelearning.ca/en/documents/ OttawaProposal.pdf

Welton, M. R. (2006). Intimations of a just learning society: From united farmers of Alberta to Henson's provincial plan in Nova Scotia. In T. Fenwick, T. Nesbit, \& B. Spencer (Eds.), Contexts of adult education: A Canadian perspective (pp. 24-35). Toronto, ON: Thompson Educational Publishing. 